\title{
Nest construction behavior by the orchid bee Euglossa hyacinthina
}

\author{
Daniel O. Wcislo', Gloria Vargas², Kate E. Ihle ${ }^{2,3}$, William T. Wcislo² \\ I 230 Appleton Place, \#555, Nashville TN 37203 USA 2 Smithsonian Tropical Research Institute, Apartado \\ 0843-03092 Balboa, Ancón, Panamá. From the USA: STRI, Unit 9100, Box 0948, DPO AA 34002-9998 \\ 3 School of Life Sciences, Arizona State University, Tempe AZ 82587 \\ Corresponding author: William T.Wcislo(WcisloW@si.edu)
}

Academic editor: Jack Neff | Received 2 October 2012 | Accepted 8 October 2012 | Published 15 October 2012

Citation: Wcislo DO, Vargas G, Ihle KE, Wcislo WT (2012) Nest construction behavior by the orchid bee Euglossa hyacinthina. Journal of Hymenoptera Research 29: 15-20. doi: 10.3897/JHR.29.4067

Orchid bees (Euglossini) are a diverse and widespread Neotropical taxon comprised of five genera and nearly 200 species (Dressler 1982; Ramírez et al. 2002; Roubik and Hanson 2004; Cameron 2004). Nests are generally dispersed or otherwise difficult to locate, so the nesting biology of most species is unknown, and knowledge of euglossine nest architecture is fragmentary (op. cit.). Some species construct nests made of mud or resin within natural or man-made cavities, while others construct free-standing nests made of resin (op. cit.). Euglossa is the most speciose genus with 129 described species (Nemésio and Rasmussen 2011), but nest architecture has been described for only 24 species $(<20 \%)$, including both free-standing and cavity nests (reviewed by Ramírez et al. 2002).

Aerial nests of Euglossa are either built on the undersides of leaves, or are topshaped and attached to plant stems (e.g., Young 1985; Eberhard 1988; Riveros et al. 2009). An example of the latter is the nest of Euglossa hyancinthina, which is attached to the side of secondary-growth plant stems. Gross nest architecture, general natural history and social behavior of E. hyacinthina have been described (Eberhard 1988; Soucy et al. 2003; Capaldi et al. 2007), but nest construction behavior has not been described for any aerial nester. During the course of other studies, we made observations on E. hyacinthina nest construction behavior, which, although preliminary, are worth summarizing here given the dearth of information about nest construction behavior in orchid bees.

Copyright Daniel O.Wcislo et al. This is an open access article distributed under the terms of the Creative Commons Attribution License 3.0 (CC-BY), which permits unrestricted use, distribution, and reproduction in any medium, provided the original author and source are credited. 


\section{Materials and methods}

We studied Euglossa hyacinthina at the species' type locality in cloud forest near Fortuna, Panamá (Chiriqui Province) (elevation, $-1400 \mathrm{~m}$ ). Nests were relatively abundant on small composites, mainly Baccharis pedunculata, between the Edwin Fabrega Hydroelectric Dam and about $2 \mathrm{~km} \mathrm{~S}$ of the Smithsonian Tropical Research Institute's Jorge L. Arauz Center for Tropical Investigations, along the side of the road running from Los Planes to Chiriqui Grande.

Nest construction behavior was recorded with a GoPro HD Hero2 video camera mounted on a support approximately $25 \mathrm{~cm}$ from the nest. A partially constructed nest was discovered on 30 August 2012, and video recordings were made from approximately 9:00 AM to 12:00 PM and 2:00 PM to 4:30 PM on 31 August, with additional photos taken on 2 September. Additional observations on cell construction were made intermittently between May 2011 and January 2012 from nests in which viewing windows were cut into the envelope. Estimates of the amount of work completed were taken from digital photos. Nests were collected very late in the afternoon, presumably when most bees were home. Nest measurements were made with a Mitutoyo digital caliper. Means are given \pm one standard deviation. Statistical tests were done using PASW Statistics v 18.0. A voucher specimen is deposited in the Museo de los Invertebrados, Universidad de Panamá, and the STRI Dry Reference Collection.

\section{Results and discussion}

Two of 18 nests were presumably recently constructed, as inferred from the light orange color of the resin and the relatively pliable wall of the envelopes, and most (17) were relatively young, in contrast to an older nest that was dark brown, and brittle, as are abandoned nests (also Eberhard 1988). Fifteen nests contained a single female, and the other three nests had 0,2 and 4 females, respectively. Nests contained from 1 to 17 cells $(\overline{\mathrm{x}}=4.17 \pm 3.96)$; the nest with the latter had 4 females. Nests collected at other times of the year at the same or a different site also included both newly constructed nests and older ones (Eberhard 1988; Soucy et al. 2003; Capaldi et al. 2007). One nest was yellowish in color and the resin presumably came from a different tree, but the sources of resin are unknown. Nests of E. nigropilosa are constructed from Clusia resin (Otero et al. 2008). Completed nests were approximately $6.25 \pm 0.6 \mathrm{~cm}$ long and 4.09 $\pm 0.25 \mathrm{~cm}$ wide near the top, with walls of equal thickness near the top of the next $(\overline{\mathrm{x}}=$ $0.93 \pm 0.23 \mathrm{~mm})$ and at the bottom $(\overline{\mathrm{x}}=0.92 \pm 0.37 \mathrm{~mm})$, contrary to nests from a Costa Rican population (Eberhard 1988). Externally, nest envelopes were characterized by vertical bands of slightly different colored resin (which may reflect differences in age), and by fine ridges (also Eberhard 1988). Internally the surface of the envelope was smooth, except for a number of small mounds of resin (Figure 1A). At least some of these mounds were caches of resin that were used in construction, but it is not known if they have any architectural significance. 
When first discovered, the nest envelope was approximately $1 / 3$ completed (Figure 1A) and grew slowly each day (Figure 1B). Only a single female worked on constructing the new nest. This female made repeated foraging trips for resin lasting from $7 \mathrm{~min} 43 \mathrm{sec}$ to $14 \mathrm{~min} 19 \mathrm{sec}(\overline{\mathrm{x}}=619 \pm 138 \mathrm{sec}, \mathrm{N}=7)$, returning to the nest with large masses of resin on the hind corbiculae, which she deposited in a small pile on the inner surface of the envelope as a temporary cache. These trips

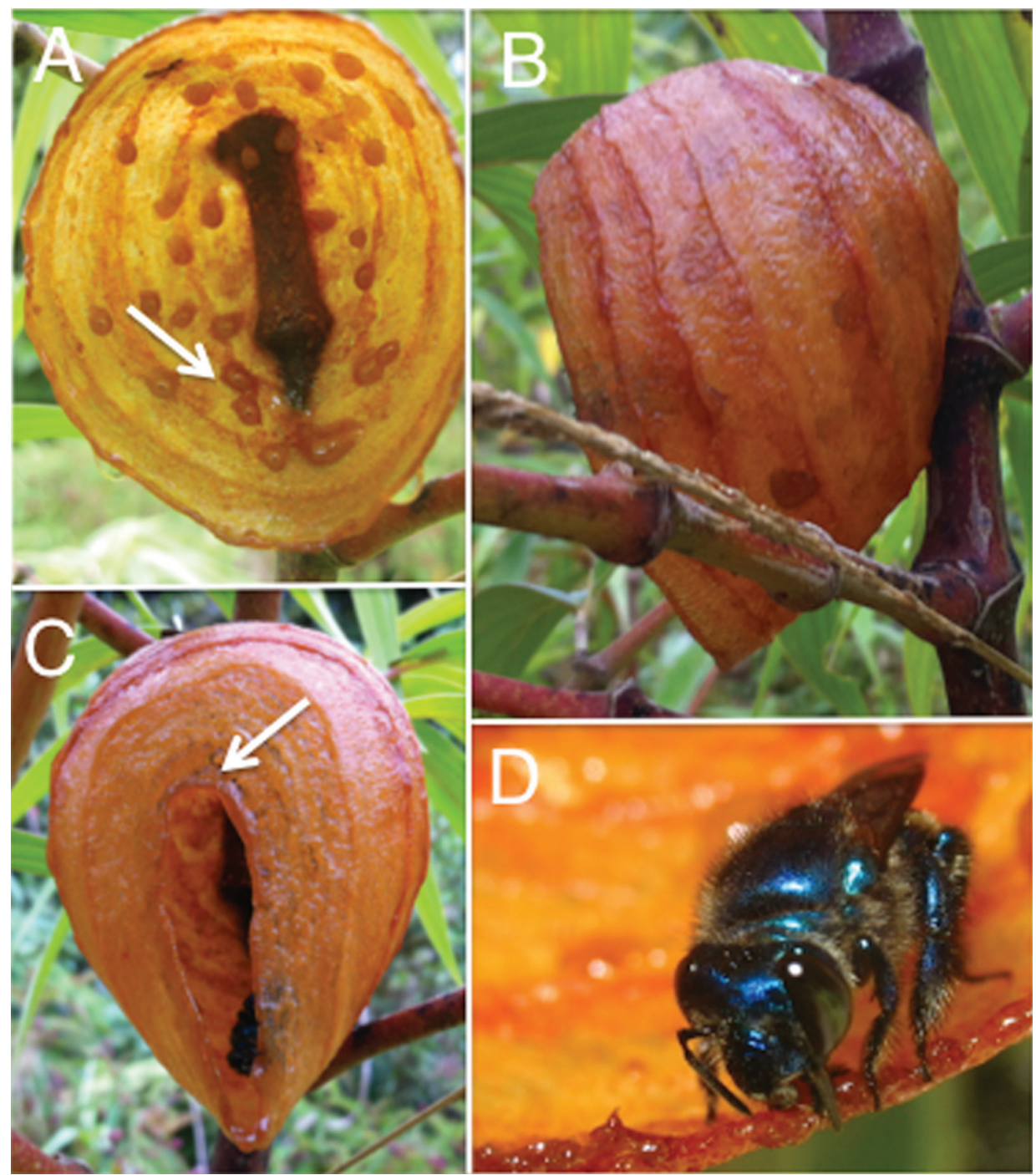

Figure I. A Interior view of a nest of Euglossa hyacinthina under construction. The dark area in the center is where the nest envelope is attached to the plant stem. The numerous droplets are caches of resin (white arrow). B The same nest the next day. C The same nest nearly completed, 3 working days after the photo in A. The white arrow points to the eave over what will become the entrance hole. D A female orchid bee shaping resin along the rim of the growing nest envelope. 


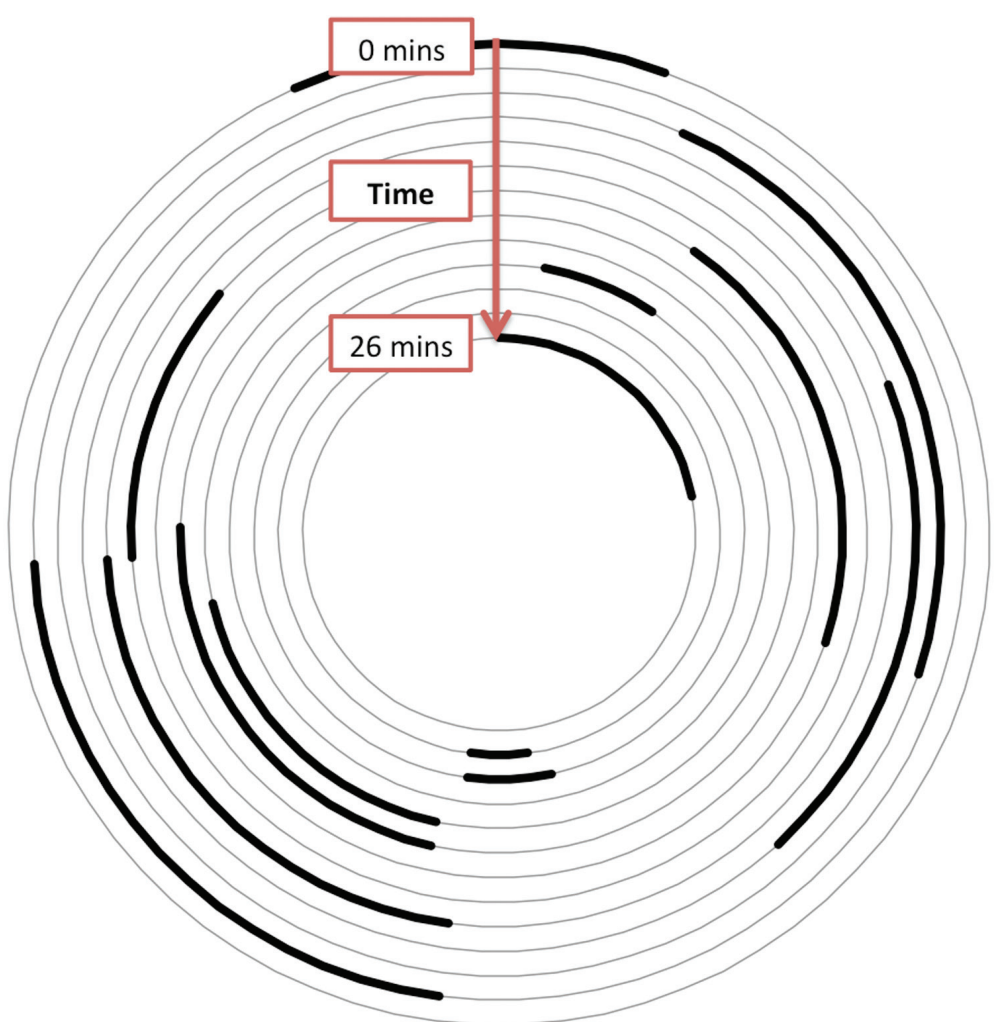

Figure 2. Graphical representation of work effort showing how the bee moves from one side of the nest to another while constructing the envelope. Each arc represents the area the bee worked in a given work session, each lasting approximately from 1 to $2 \mathrm{~min}$. The concentric arcs represent 13 sequential work bouts during a 26 min session of construction; the outer-most arc is the starting position at the beginning of the session and the inner-most one is the ending position.

were faster than resin foraging in other Euglossa [means of $24.3 \mathrm{~min}$ and $18.2 \mathrm{~min}$, respectively, for Euglossa atroveneta (Ramírez-Arriaga et al. 1996) and E. nigropilosa (Otero et al. 2008)] or a larger bee, Eulaema meriana (mean = $32 \mathrm{~min}$ ) (Cameron and Ramírez 2001), but whether or not these differences are related to relative abundance of resin is not known. The bee made other trips away from the nest and returned without any building materials (range: $4 \mathrm{~min} 30 \mathrm{sec}$ to $8 \mathrm{~min} 51 \mathrm{sec} ;(\overline{\mathrm{x}}=$ $435 \pm 94 \mathrm{sec}, \mathrm{N}=6$ ); these were shorter than resin foraging trips (Mann-Whitney $\mathrm{U}, \mathrm{P}=0.015)$. Following each resin foraging trip, the bee worked on nest construction for $9 \min 49 \mathrm{sec}$ to $21 \mathrm{~min} 59 \mathrm{sec}(\mathrm{x}=939 \pm 252 \mathrm{sec}, \mathrm{N}=6)$ before leaving the nest again, roughly similar to Eu. meriana (mean, $21 \mathrm{~min}$ ) (Cameron and Ramírez 2001). Following non-resin foraging trips each construction session lasted equally long as those following resin-foraging trips, from $10 \mathrm{~min} 21 \mathrm{sec}$ to $26 \mathrm{~min} 12 \mathrm{sec}$ $(\overline{\mathrm{x}}=957 \pm 393 \mathrm{sec}, \mathrm{N}=5)$ (Mann-Whitney U, NS).

During construction the bee walked to the cache of resin and removed a small piece with her mandibles, and then went to the edge of the nest envelope, where she 
applied the resin. She then formed it by keeping the inner surface of one mandible in contact with the edge of the envelope while the other mandible was repeatedly closed; along with subtle head movements this action apparently pushed resin against the concave inner surface of the other mandible (Figure 1D). Although sticky to human hands, the resin did not stick to the bee. Within a given session of construction, the bee did not extend the envelope only at a single spot, or extend the envelope in a continuous manner, but moved about the envelope between visits to the resin cache, from one side to the other with short bouts of resin-shaping (Figure 2). When females added new material to the previous work there was a thin band of slightly thicker resin that was visible externally as a ridge, which was then extended to a thinner layer by squeezing the resin with the mandibles (a video clip of nest construction behavior is given in the Supplemental Materials). Early on the 4th day after the nest was discovered the envelope was nearly completed, including a small roof defining the top of the entrance hole (Figure 1C); we infer that nest envelope construction takes approximately 6 days. Intermittent observations show that cell construction is completed in less than 2 ( 1 cell) or 3 days ( 4 cells).

Much of the very limited information available on orchid bee nest construction comes from studies of cavity nesters in artificial observation boxes, so few comparisons are possible. Euglossa hyacinthina offers an excellent opportunity for detailed studies of building behavior in corbiculate bees with relatively simple architecture, for comparisons with Apis, for which architecture reaches its zenith in the perfect geometric structure of honey bee comb (Gould and Gould 2007).

\section{Acknowledgements}

We thank the Smithsonian Tropical Research Institute (STRI) support staff for logistic help, Donna Conlon for the loan of camera equipment, and the Autoridad Nacional del Medioambiente of Panama for research and collecting permits. The research was supported by general STRI funds to WTW. KEI was supported by a grant from the Arizona State University-Smithsonian Institution collaboration.

\section{References}

Cameron SA (2004) Phylogeny and biology of neotropical orchid bees. Annual Review of Entomology 49: 377-404. doi: 10.1146/annurev.ento.49.072103.115855

Cameron SA, Ramírez S (2001) Nest architecture and nesting ecology of the orchid bee Eulaema meriana (Hymenoptera: Apinae: Euglossini). Journal of the Kansas Entomological Society 74: 142-165.

Capaldi E, Flynn CJ, Wcislo WT (2007) Sex ratio and nest observations of Euglossa hyacinthina (Hymenoptera, Apidae, Euglossini). Journal of the Kansas Entomological Society 80: 395-399. doi: 10.2317/0022-8567(2007)80[395:SRANOO]2.0.CO;2 
Dressler RL (1982) Biology of the orchid bees (Euglossini). Annual Review of Ecology and Systematics 13: 373-394. doi: 10.1146/annurev.es.13.110182.002105

Eberhard WG (1988) Group nesting in two species of Euglossa bees (Hymenoptera: Apidae). Journal of the Kansas Entomological Society 61: 406-11.

Gould JL, Gould CG (2007) Animal Architects: Building and the Evolution of Intelligence. Basic Books, NY, 336 pp.

Nemésio A, Rasmussen C (2011) Nomenclatural issues in the orchid bees (Hymenoptera: Apidae: Euglossina) and an updated catalogue. Zootaxa 3006: 1-42.

Otero JT, Ulloa-Chacón P, Silverstone-Sopkin P, Giray T (2008) Group nesting and individual variation in behavior and physiology in the orchid bee Euglossa nigropilosa Moure (Hymenoptera, Apidae). Insectes Sociaux 55: 320-328. doi: 10.1007/s00040-008-1009-2

Ramírez S, Dressler RL, Ospina M (2002) Abejas euglosinas (Hymenoptera: Apidae) de la región Neotropical: listado de especies con notas sobre su biología. Biota Colombiana 3: 7-118.

Ramírez-Arriaga E, Cuadruelo-Aguilar JI, Martínez Hernández M (1996) Nest structure and parasite of Euglossa atroveneta Dressler (Apidae: Bombinae: Euglossini) at Unión Juárez, Chiapas, México. Journal of the Kansas Entomological Society 69: 144-152.

Riveros AJ, Hernandez J, Wcislo WT (2009) Nesting biology of Euglossa dodsoni Moure in Panama. Journal of the Kansas Entomological Society 82: 210-214. doi: 10.2317/ JkES808.15.1

Roubik DW, Hanson PE (2004) Abejas de Orquídeas de la América Tropical. Instituto Nacional de Biodiversidad, Heredia Costa Rica.

Soucy SL, Giray T, Roubik DW (2003) Solitary and group-nesting in the orchid bee, Euglossa hyacinthina (Hymenoptera, Apidae). Insectes Sociaux 50: 248-255. doi: 10.1007/s00040003-0670-8

Young A (1985) Notes on the nest structure and emergence of Euglossa turbinifex Dressler (Hymenoptera: Apidae: Bombinae: Euglossini) in Costa Rica. Journal of the Kansas Entomological Society 58: 538-543.

\section{Appendix}

A Quicktime video of a female Euglossa hyacinthina working on the construction of her nest envelope. doi: 10.3897/JHR.29.4067.app

Citation: Wcislo DO, Vargas G, Ihle KE, Wcislo WT (2012) Nest construction behavior by the orchid bee Euglossa hyacinthina. Journal of Hymenoptera Research 29: 15-20. doi: 10.3897/JHR.29.4067.app 